\title{
From “Cogito Ergo Sum” to “Vivo Ergo Sum”: Current Theoretical Trends and Changing Perspectives in Leadership
}

\author{
Ozkan Karaaslan \\ Economic and Social Studies Department, Kozminski University, Warsaw, Poland \\ Email: ozkankaraaslan@gmail.com
}

Received 20 November 2015; accepted 18 December 2015; published 21 December 2015

Copyright (C) 2015 by author and Scientific Research Publishing Inc.

This work is licensed under the Creative Commons Attribution International License (CC BY). http://creativecommons.org/licenses/by/4.0/

(c) (i) Open Access

\begin{abstract}
The aim of this paper is to review recent developments in leadership theories from paradigm perspective and introduce the new frontiers and challenges of leadership theories and practice. Considering that organizational analysis is rooted in different social science paradigms, "scientization" was likely to result in hegemony of a single paradigm in management field-and in specific leadership studies-by suppressing knowledge claims of other paradigms. In conjunction with this, the study attempted to verify whether the leadership field is dominated by modernistpositivist approach by analyzing the trend in last 15 years from this perspective. Findings of the review significantly demonstrated that the recent developments in the field can be described as a transition from a modernist-positivist approach towards more balanced fashion which employs both retrospective and interpretive approach in leadership studies. However, it is also underlined that integrative perspectives that consider how disparate leadership theories-66 different leadership theories in specific-relate or operate simultaneously to influence the emergence of leadership phenomena is crucial.
\end{abstract}

\section{Keywords}

Leadership Review, Established Theories, Emerging Theories, Leadership Frontiers, Leadership Challenges

\section{Introduction}

Scholarly research on the topic of leadership has enjoyed a significant increase over the last years, which has consequently ended in the emergence of numerous diverse leadership theories. The various types of leadership 
theories in the contemporary literature and its wide range and abundance can easily be identified by having a quick search on the relevant journals. Having been juxtaposed by Dinh et al. (2014)'s study resulting in 66 particular theories (both established and emerging), and demonstrated the current trends and changing perspective, prevalent implications trigger the questions concerning the new frontiers of leadership and the fashion of recent research efforts in this changing perspectives. As an observed necessity, directing the focus to the fashion of leadership theories promises a clearer understanding of interpreting the trends in the literature. Aiming to this end, this study expands above study as it associates the articles from same top-tier journals for the period between 2000 and first half of the year 2015 and adding a paradigm perspective to these efforts. In this conjunction, from modernism to interpretivism, and post-modernism, the lenses which shape the diverse leadership theories are sought and an increasing tendency towards interpretivism as elaborated below is observed.

By the inception of modernism, Aristotelian approach which is examining "logos" (rationality), "ethos" (ethics) and "pathos" (senses) as components of a whole lost its importance. While modernist-positivist approach asserted rationalism as the legitimate source of science in the effort of "scientize", ethics and senses were advertised to be normative and non-scientific (Yildirim, 2002). Efforts to "scientize" social and management studies in the sense of adopting methods of natural sciences had undermined the development of a more critical understanding of underlying phenomena ${ }^{1}$. Subsequently, by the turn of mid-20th Century, new occurrences in history of science and philosophy, decreased trust to Cartesian models. Consequently this led to debut of interpretivisim and post-modernism which retrospectively brought the scholarly attention back to ethos and pathos. This development was characterized by the shift from Cartesian thinking which emphasized "logos" in the form of "cogito ergo sum" towards the other end of the continuum which emphasized "ethos" and "pathos" in the form of "vivo ergo sum". In parallel with other social sciences, management and organization theory-in particular leadership- - has been affected by these developments. It is now understood that efforts to explain the leadership phenomena solely with rational models are inadequate, since leadership has "soft" aspects that can be social, cultural and even emotional (Kozminski \& Jemielniak, 2013: p. 17).

Being a social science, management field experienced continuing developments. In other words, as Kozminski (2008: p. 11) puts, "the history of management theory and practice is never-ending story of incremental changes and adjustments to dynamic environments. It is characterized by a series of transitions: from structures, processes, policies, mind-sets and cultures failing to meet environmental challenges towards better fit and satisfactory performance." It is now widely accepted fact that there is an increasing tendency from structures and systems towards culture, ethics, and symbolism which can be clearly observed within recent management and leadership literature (Dinh et al., 2014, also see Table 1). Now that, it is maintained by many prominent academicians that in order to be able to interpret people in organizations, aesthetic consciousness is crucial to substitute rational models of human motivation and performance (i.e.: Hatch, Kostera, \& Kozminski, 2007).

Table 1. Number of leadership research articles published in 10 top-tier journals (2000-2015).

\begin{tabular}{cc}
\hline Journal & Numbers of articles \\
\hline Academy of Management Journal & 53 \\
Academy of Management Review & 10 \\
Administrative Science Quarterly & 36 \\
American Psychologist & 14 \\
Journal of Applied Psychology & 140 \\
Journal of Management & 45 \\
Organizational Behavior and Human Decision Processes & 30 \\
Organizational Science & 8 \\
Personnel Psychology & 30 \\
The Leadership Quarterly & 43 \\
\hline
\end{tabular}

\footnotetext{
${ }^{1}$ For more information on the related topics, see (Yildirim, 2002) and/or (Clegg \& Hardy, 1999).
} 
There is a substantially recognizable stress upon the soft aspects of management and leadership studies in recent years. As Hatch et al. (2007: p. 2) notes, "The most influential business leaders of late twentieth century indicate that the artful side of management is reasserting itself. So it was that we set our sights on a fresh look at an old theme: the art of management. What makes it fresh is that we take up where Adam Smith left off, expanding the domain of art into that of aesthetics. Put another way, we seek not only to reassert the artful side of management, but to explore the aesthetics of business leadership as well." Aesthetics as a term that covers interests continuum from the creative to ethical highlights the humanistic aspect of leadership and to emphasize the importance for society of using virtue as a criterion for judging business leaders (Hatch, Kostera, \& Kozminski, 2007).

The recent developments in management and leadership studies can be described as a transition from a modernist-positivist theory to interpretive approach. It is a fact that many anthropologist and religious scholars now believe that, wherever culture is found, art and religion will attend its founding, means to us that managerial culture should also evidence artistic and spiritual origins (Hatch, Kostera, \& Kozminski, 2007: p. 6). In relevancy with this, such a differentiation in the paradigmal approaches has resulted in the development of diverse leadership theories (Dinh et al., 2014). It has been common to encounter a study aiming to understand how micro processes, such as perceptions, emotions, and cognitions and macro processes, such as the social-relational context, dynamically affect follower and leader outcomes.

As Gardner and colleagues (2010) highlighted in their 20-year review of The Leadership Quarterly (LQ), leadership field has grown exponentially in the new millennium by the attracted talented scholars and practitioners from around the globe who have drastically changed the way leadership phenomena understood. This attraction has consequently resulted in the development of diverse leadership theories. In order to be able to examine this diversity and to review of established and developing theories since the beginning of the new millennium, this paper was designed. Following the trace of Gardner et al. (2010) and Dinh et al. (2014) and expanding the framework provided by Dinh et al. (2014) in which Dinh and her colleagues conducted an extensive qualitative review of leadership theory across 10 top-tier academic publishing outlets; this paper aims to take the stock of new millennium's leadership trends from the paradigm perspective.

To accomplish study' objective, this paper is partitioned into five major sections. Following the introduction, the methodology section describes data collection method and sample, as well as coding procedures and categories are briefed. In the results section, an overview of the trends in leadership theories that have appeared since the beginning of the new millennium is provided under two main parts which are the status of established leadership theories and emerging leadership theories. Subsequently, in the findings and discussion section, more thorough descriptions of the theories that have remained at the forefront of research and theories that have (re)surfaced since 2000 are provided, while recent trends in the field and relevant implications are discussed. Finally, a conclusion regarding the overall literature underlining the recent tendencies is offered and suggestions is made for the development of more integrative leadership theory and research, as well as address the practical and theoretical implications of this review to guide future research.

\section{Methodology}

As aforementioned, Gardner et al. (2010) and Dinh et al. (2014)'s traces were tracked for this study. Following Gardner et al. (2010), Dinh and colleagues (2014) in their review searched the 10 journals identified known for publishing leadership research and that also have high impact factors and regularly appear at the top of journal ranking lists in the field of organizational behavior (namely; Leadership Quarterly (LQ), Administrative Science Quarterly, American Psychologist, Journal of Management, Academy of Management Journal, Academy of Management Review, Journal of Applied Psychology, Organizational Behavior and Human Decision Processes, Organizational Science, and Personnel Psychology). They performed a manual search for leadership, restricting search to articles published between 2000 and September 2012.Whilst, this study expands Dinh et al. (2014)'s and associates the articles from same top-tier journals for the period between 2000 and June 2015.

\subsection{Sample}

For data collection, Dinh and colleagues (2014) techniques were followed and as a first step, in order to gather the data for the remaining period, relevant journals were searched manually via their web pages. Having identified the articles containing leadership in their title or keywords the articles were ear-marked for further inquiry. As a second step, abstracts of ear-marked articles were examined under the guidelines from the previous practice, 
screening these articles and applying the following two selection criteria (1. Verifying whether the article is original research, whether qualitative, quantitative, theoretical, or methodological, in that eliminating such items as letters, editorials, and book reviews. 2. Reviewing the abstracts to determine if leadership were the primary focus of the articles). Thirdly, thematic categories which they had fallen under were identified. Finally, extracted data from the period between November 2012-June 2015 was aggregated to the ones from 2000-October 2012.

In their research Dinh et al. (2014) yielded 989 total hits in their first step. In addition to this figure, the remaining period for this study yielded 113 total hits. Those that failed either or both of these two selection criteria (18 articles) were excluded, leaving 95 articles in addition to 752 (237 had excluded) articles from the previous study in aggregate of 847.

Table 1 demonstrates the number of articles found in each journal. LQ, as a dedicated journal to the publication of leadership research, dominated the dataset (521 articles), which is expectable. Journal of Applied Psychology ranked second (140 articles) in terms of the number of published leadership research, and amounted to notably more articles than the remainder of journals examined. Organizational Science (8 articles) and Academy of Management Review (10 articles) published the fewest number of leadership articles within the dataset.

\subsection{Coding Procedures and Categories}

In terms of coding the inclusively incorporated dataset found in 10 top-tier journals, this paper employs Dinh et al. (2014)'s taxonomy. In this study, the articles grouped categorically under established and emergent theories and thematically within below broader thematic categories. Following this taxonomy, in this paper, the established leadership theories categorical group contains: Neo-charismatic theories, Leadership and Information Processing, Social Exchange/Relational Leadership Theories, Dispositional/Trait Theories, Leadership and Diversity; Cross-Cultural Leadership, Follower-Centric Leadership Theories, Behavioral Theories, Contingency Theories and Power and Influence of Leadership thematic groups.

Whilst, the emerging leadership theories categorical group contains: Strategic Leadership, Team Leadership, Contextual, Complexity and System Perspectives of Leadership, Leader Emergence and Development, Ethical/ Moral Leadership Theories, Leading for Creativity, Innovation and Change, Identity-Based Leadership Theories and Other Nascent Approaches. Each thematic group has also its own affiliated theories/sub-thematic group which can be seen in Table 2. For more detailed figures for the taxonomy, it can be referred to Dinh et al. (2014), Appendix A.

There were also some other approaches under emerging theories which were not falling under any thematic category. These nascent approaches are listed separately as follows: Emotions and leadership, destructive/ abusive/toxic leadership, biological approaches to leadership, E-leadership, leader error and recovery and entrepreneurial leadership.

\section{Results}

Having grouped the theories under 2 different categorical and 17 thematic groups, and applying screening to these additional 95 articles against the coding convention above, the screening yielded the aggregated results demonstrated in Table $3^{2}$.

Within the established leadership theories cluster; neo-charismatic theories, which are rooted historically to charismatic leadership theory, received the most attention from scholars in the new millennium (total 341 instances), with transformational leadership and charismatic leadership, respectively, representing the dominant type of interest. Leadership and information processing received the second largest quantity of frequency (total 211 instances), with leader and follower cognitions and implicit leadership. Together, this category incorporates also the cognitive structures of leaders, followers, and decision-making. Social exchange/relational theories (179 instances) together with dispositional/trait theories (184) were also considerably frequent. Reflecting a tendency towards greater social equality, leadership and diversity, and cross-cultural studies comprised another common thematic category (97 instances). Follower-centric leadership theories (77 instances) also reflect this trend. On the other hand, some dwindling area of research interest observed namely the behavioral and the classic contingency theory thematic categories. Collectively, it was found 76 and 62 instances respectively. In the bottom, there was found to be the power and influence theories with 61 instances.

\footnotetext{
${ }^{2}$ The total frequency exceeded the number of articles since articles often employed multiple theoretical frameworks. Percentages were calculated by using the frequency divided by the total number of articles, i.e. 847.
} 
Table 2. Categorical and thematic groups/sub-groups of leadership theories.

\begin{tabular}{|c|c|}
\hline Established Theories & Emerging Theories \\
\hline Neo-Charismatic Theories & Strategic Leadership \\
\hline Transformational lesdership & Strategic/top executive \\
\hline Charismatic leadership & Upper echelons theory \\
\hline Transactional leadership & Public leadership \\
\hline \multicolumn{2}{|l|}{ Ideological/pragmatic, outstanding leadership } \\
\hline Self-sacrificing leadership & Team Leadership \\
\hline Pygmalion effects & Leadership in team and decision groups \\
\hline \multicolumn{2}{|l|}{ Inspirational leadership } \\
\hline Leadership and Information Processing & Contextual, Complexity and System Perspectives of Leadership \\
\hline Leader and follower cognition & Contextual theories of leadership \\
\hline Implicit leadership & Social network theories of leadership \\
\hline Attribution theories of leadership & Complexity theories of leadership \\
\hline Information processing and decision making & Integrative leadership \\
\hline Social Exchange/Relational Leadership Theorie & Leader Emergence and Development \\
\hline Leader-member exchange (LMX) & Leadership development \\
\hline Relational leadership & Leadership emergence \\
\hline \multicolumn{2}{|l|}{ Vertical dyadic linkage (VDL) } \\
\hline \multicolumn{2}{|l|}{ Individualized leadership } \\
\hline Dispositional/Trait Theories & Ethical/Moral Leadership Theories \\
\hline Trait theories & Authentic leadership theory \\
\hline Leadership skills/competence & Ethical leadership theory \\
\hline Leader motive profile theory & Leader motive profile theory \\
\hline Leadership and Diversity, Cross-Cultural & Servant leadership theory \\
\hline Leadership and diversity, & Leading for Creativity, Innovation and Change \\
\hline Cross-cultural leadership & Leading for creativity and innovation \\
\hline Follower-Centric Leadership Theories & Leading organizational change \\
\hline Followership theories & Leading for organizational learning and knowledge \\
\hline \multicolumn{2}{|l|}{ Romance of leadership } \\
\hline Aesthetic leadership & Identity-Based Leadership Theories \\
\hline Behavioral Theories & Social identity theory of leadership \\
\hline Participative, shared leadership; delegation and empowerment & Identity and identification process theories of leadership \\
\hline
\end{tabular}

(Source: Dinh et.al, 2014). 
Table 3. Frequencies of leadership theories under categorical and thematic groups (2000-2015).

\begin{tabular}{|c|c|c|c|c|c|c|c|}
\hline Established Theories & Freq. & $\%$ & Rank & Emerging Theories & Freq. & $\%$ & Rank \\
\hline Neo-Charismatic Theories & 341 & 40 & 1 & Strategic Leadership & 211 & 25 & 1 \\
\hline Leadership and Information Processing & 211 & 25 & 2 & Team Leadership & 129 & 15 & 2 \\
\hline $\begin{array}{l}\text { Social Exchange/Relational } \\
\text { Leadership Theories }\end{array}$ & 179 & 21 & 4 & $\begin{array}{l}\text { Contextual, Complexity and } \\
\text { System Perspectives }\end{array}$ & 121 & 14 & 4 \\
\hline Dispositional/Trait Theories & 184 & 22 & 3 & Leader Emergence and Development & 116 & 14 & 5 \\
\hline $\begin{array}{l}\text { Leadership and Diversity; } \\
\text { Cross-Cultural Leadership }\end{array}$ & 97 & 11 & 5 & Ethical/Moral Leadership Theories & 126 & 15 & 3 \\
\hline Follower-Centric Leadership Theories & 77 & 9 & 6 & Leading for Creativity, Innovation and Change & 87 & 10 & 6 \\
\hline Behavioral Theories & 76 & 9 & 7 & Identity-Based Leadership Theories & 68 & 8 & 7 \\
\hline Contingency Theories & 62 & 7 & 8 & Other Nascent Approaches & 115 & 13 & 8 \\
\hline Power and Influence Theories & 61 & 7 & 9 & & & & \\
\hline
\end{tabular}

In the scope of emerging leadership theories; strategic leadership approaches is the most prolific of the emerging leadership theories (211 instances) of any of the emerging thematic categories, while team leadership has seen a significant increase in the number of recent research (129) instances. The ethical/moral values-based content of a leader's behavior is the third most prolific of the emerging leadership approaches with 126 instances. Increasing attention with regard to the systems thematic category which consists of contextual, complexity, social network and integrative approaches (121 instances) is also noted. Similarly, extensive activity in the leader emergence and development thematic category (116 instances) is significant, as well. Leading for creativity, innovation and change, together with the identity based leadership theories have also considerably captured the researchers interest (87 and 68 instances, respectively). There are number of other emerging approaches that was not classified into a larger thematic category with 118 instances (Emotions and leadership (66 instances, 8\%), destructive/abusive/toxic leadership (24 instances, 3\%), biological approaches to leadership (instances 12, 2\%), E-leadership (8 instances, 1\%), leader error and recovery (4 instances, $0.5 \%$ ) and entrepreneurial leadership (4 instances, $0.5 \%$ ). Some of these deserve special recognition because of their increasing popularity, which will be detailed below in findings and discussion.

\section{Findings and Discussion}

Results of the study shows that several theories continue to attract scholarly interest for understanding specific leadership phenomena (i.e.: neo-charismatic leadership theories, leadership and information processing), while interest in some other theoretical domains has decreased in recent years (i.e.: contingency theory, behavioral approaches). It is also identified that some research domains that have grown in popularity over the past decade, suggesting growth of new emergent theories (e.g., spiritual leadership, leadership emergence). Altogether, present study asserts that leadership field has proliferated since the beginning of new millennium, which signifies that it is easy to predict that this growth will continue in the coming decades.

It is also seen that leadership researchers have begun to appreciate the social context in which the leader operates and his or her effect on the team as a whole, addressing a global shortcoming of leadership research that often criticized to be operating in the dyadic level. Such as, complexity \& system theories, and identity based perspectives are seeing an impressive increase which implies the increasing importance of interpretive paradigm in the new millennium. Similarly, The emotions and leadership and spiritual leadership category highlights the prolific interest to those soft aspects which refers to pathos and ethos, respectively. Still, there is established leadership theories’ dominancy, whereas emerging leadership theories closing the gap.

\subsection{Status of Established Leadership Theories}

Within the established leadership theories cluster; neo-charismatic theories are keeping attracting attention from scholars in the period of inquiry with transformational leadership and charismatic leadership, respectively, 
representing the main forms of interest. These articles studies transformational and/or charismatic leadership topics, e.g., concepts of charisma, consequences of charismatic leadership. For detailed summary it can be referred to Shin \& Zhou (2003) in which authors provide an overview of transformational leadership and its relation with worker outcomes and Mumford et al. (2008) for the charismatic leadership. In addition, this thematic category also includes inspirational, Pygmalion effects, visionary, self-sacrificing and ideological/pragmatic, full-range and outstanding leadership theories.

Leadership and information processing refers to cognitive approaches to information processing and decision making processes in leadership including attribution theories, leader and follower cognitions (e.g., perceptions), the connectionist approach, and implicit leadership theories (Lord, Hannah, \& Jennings, 2005). For more detail on symbolic, connectionist, and embodied perspectives of leadership it can be referred to Lord \& Shondrick (2011). This category questions the cognitive structures of leaders, followers, and decision-making. These research questions have been captured the interest of the researchers since the late 1970s and findings of this paper suggest that it is continued.

Findings also suggest that social exchange/relational theories are still quite common. Leader-member exchange (LMX), as the archetypal social exchange leader-follower dyadic approach together with relational leadership and vertical dyad linkage investigates the quality of the relationship experienced within the dyad, in a relational and constructive and interpretive manner. For more comprehensive information regarding relational theories please see Uhl-Bien (2006).

Dispositional/trait theories comprised another common thematic category within established theories. However, as stated by Dinh et al. (2014) in the vast majority of the samples investigated traits found to be in concert with at least one other leadership approach in the taxonomy. This thematic category includes articles that examine individual differences in leaders like specific traits, abilities or clusters of abilities that contribute to leadership effectiveness. Category includes the traditional trait approach (Zaccaro, 2007), as well as other newer approaches, namely nature of managerial traits, managerial attributes, skills and competence, situational relevance of skills, and leader motive profile theory. Judge \& Bono (2000) offer a thorough review of the trait based approaches as well as a trait based model of leadership emergence and effectiveness, with its mediators and moderators.

Having mentioned the concern with greater social equality—which leads to prominence of the leadership and diversity, and cross-cultural themes - these topics continue to be of wide interest. Diversity theories concisely investigate the experiences of women and minorities in leadership positions, and of diverse followers within domestic borders, e.g., the benefits of more women leaders, the challenges facing women in leadership roles (Eagly \& Chin, 2010). While, cross-cultural thematic category is related to comparing the leadership processes of one culture to another in a way how settings/culture, country \& attributes of leadership, universality, cultural \& institutional changes, differences in Leadership across cultures, leadership in the multinational firms can be examined (Kirkman et al., 2009).

Similarly, follower-centric leadership theories also reflect the trend of these social equity concerns', and a concern with shared leadership, seems to be catching researchers attention in the period of inquiry. These theories prioritize the follower in the leader-follower pairing, specifically; it investigates follower attributes related to the leadership process (e.g., identity, motivation, and values), the active roles follower play in leader-follower dynamics, romance of leadership, and follower outcomes (Howell \& Shamir, 2005). In their taxonomy, Dinh et al. (2014) included articles with aesthetic perspectives in leadership that investigated follower's subjective evaluation of leader qualities through aesthetic senses in this category.

Behavioral approach consists of initiating structure and consideration has attracted less interest during the time period of inquiry. This thematic category focuses on research using the leadership behavior frameworks of The Ohio State University Leadership Studies and Michigan Leadership Studies (Carson, Tesluk, \& Marrone, 2007). As well as, nature and consequences of participative, shared leadership, delegation, empowerment of leadership, studies on task-oriented behavior and initiating structure, are also focus of this thematic group (House \& Aditya, 1997).

Another area of decreasing research interest is the classic contingency theory thematic category. This thematic category includes articles where the leaders adjusted to the situation, or adjusted the situation to fit themselves (for a comprehensive study see Vroom \& Jago, 2007). And according to Dinh et al. (2014) this finding is a notable on as compared to previous studies in which contingency theories were shown among the dominant approaches in comprehensive reviews of the leadership literature before the year 2000 (please see Porter \& 
McLaughlin, 2006 for details).

The concepts of power and influence, power types and sources, consequences of position and personal power, impression management and influence tactics, and political skills constitutes the power and influence (Treadway et al., 2004). In this thematic category, dwindling research is also notable.

\subsection{Status of Emerging Leadership Theories}

In the scope of emerging leadership theories; strategic leadership theories are found to be most attractive thematic category for the leadership researchers within the emerging leadership theories. Gardner and colleagues (2010) underline that this is a significant shift in research interest given the fact that this was an underresearched topic, prior to the present millennium. This thematic category focuses on leadership phenomena at the highest levels of organizations and how executive leaders influence their organizations' performance (Ruvio, Rosenblatt, \& Hertz-Lazarowitz, 2010). In these studies, the focal level of analysis consists of CEO or other top leader and/or top-management teams at the higher echelon levels of the organization (Vera \& Crossan, 2004).

Team leadership has also seen a substantial increase in the number of recent research in conjunction with the above tendency in an understanding that much strategy formation occurs within top management teams (Denis, Lamothe, \& Langley, 2001). This thematic category primarily focus on teams, the level of analysis focus on teams and groups at the mid- and lower-level echelons of the organization (Mehra et al., 2006). Moreover, Dinh and colleagues (2014) notes in their review that team approach is frequently combined with more established theories which suggests that leadership researchers are beginning to appreciate the social context in which the leaders operate and their effect on the team as a whole. This finding is addressing a global shortcoming of leadership research that often operates at the dyadic level.

Complexity and systems leadership theories include complexity theory, with the focus on the concept of complex adaptive systems and on how complexity theory can be useful in leaders' success in turbulent environments (Uhl-Bien, Marion, \& McKelvey, 2007). They also includes contextual, social network and integrative approaches, each of which attempts to capture different aspects of the contextual features. Having been found the third most prolific of the emerging leadership approach, this thematic category and context of leadership can be said to be no longer the neglected side of leadership.

Leader emergence and development thematic category has also received a notable interest over the last 15 years. This thematic category mainly consists of leadership development in which an organization increases within its membership social capital resources necessary to engage in leadership activities, and leadership emergence in which the question who, and under what conditions, will be recognized as a leader. Those articles attempt to define pathways or processes by which leaders came to possess leadership capacity and follower recognition of leadership status. For more comprehensive review, see Day, 2001.

Ethical/moral leadership theories encompass leadership theories that amplify on altruistic behaviors. These theories of ethical leadership investigate leader moral priorities: including how an ethical orientation toward leadership is developed, how an ethical approach to leadership is important, the consequences of ethical leadership and how it can be sustained. Authentic, servant and spiritual leadership theories are also classified in this thematic category (Liden et al., 2008). As previously mentioned, there is increased concern in leadership literature with regard to the ethical/moral values-based content of a leader's behavior. This category's leadership theories, which together share common interest in positive, humanistic behaviors attempts to address another shortcoming of leadership research identified at the close of the last millennium. Since, many extant theories, including transformational leadership, failed to properly investigate altruistic leader behaviors (Yukl, 2008). Within this category, spiritual leadership which encompasses the notion that leaders embody a vision, practice altruistic love, and instill hope, faith, and perseverance in attaining organizational goals, forms a good example of shift from logos to pathos. As well as, ethical leadership exemplifies the shift from logos to ethos.

Identity based perspectives are also yielding an impressive increase in interest as the new millennium. This thematic category includes self-concept and social identity approaches to leadership, i.e., studies adopting the new introduced work of Hogg (2001) on leader categorization theory and studies adopting other social identity and self-concept frameworks. Social identity theory of leadership describes the emergence of a leader as being based on a group member's resemblance to a prototypical leader as determined by other group members -in an interpretive manner.

Leading for creativity \& change has also received considerable interest of the leadership researcher. Articles 
in this thematic category investigate creative leadership processes from a number of perspectives, encompassing topics like innovation and organizational learning. They also deals with leader's roles in organizational change, or larger social changes in society or government, i.e., developing a vision, implementing changes, and influencing organizational culture (Mumford et al., 2008). These aspects like social change, influencing organizational culture recalls for interpretive insights.

In addition, there are still some more emergent leadership theories that were not eligible to be classified into a larger thematic category. Having grouped under other nascent theories, four of these theories, deserve special recognition, since they are increasingly attracting research interest. Firstly, emotions and leadership category encompass leader's and followers' affect, and influences on that emotions, both positively and negatively (Bono \& Ilies, 2006). This trend reflects the tendency towards aesthetic and pathos side of leadership studies. Secondly, destructive leadership covers cases where leaders misbehaved, acted in ways contrary to the well-being of followers and/or the organization, and the setting where there are destructive followership, as well (Einarsen, Aasland, \& Skogstad, 2007). This category can be said to be also a reply to ethical calls for leadership studies. Thirdly, biological approaches to leadership which are using a biological/neurological approach to examine the genetic impacts on leadership emergence, development and effectiveness such as articles using behavioral genetics work with twin designs was found to be emerging (for comprehensive information see Waldman, Balthazard, \& Peterson, 2011). Lastly, E-leadership theories which are encompassing the study of leadership effects of task, technology and distance in virtual space are significantly emergent (see Golden, Veiga, \& Dino, 2008 for a E-leadership study).

\section{Conclusion}

As Dinh et al. (2014) highlight in their review that leaders are interpreted to be influentially determining their organizations' fate through their actions. Given this attached importance, numerous scholars across different disciplines have contributed to the rapid proliferation of leadership research over the last decade. As this study has shown that since the beginning of the new millennium, growth of emerging leadership theories such as neurological perspectives on leadership, and the continued prolific expansion of theories related to strategic leadership, leading for creativity and innovation, and toxic/dark leadership have been witnessed. Whereas, several well established leadership theories continue to attract the interest of the field including neo-charismatic, information processing, trait, and leader-follower exchange theories. Nevertheless, some other leadership theories have not enjoyed significant growth, including behavioral approaches, contingency theory, and path-goal theory. Overall, the growth and development of the leadership field are substantially significant and present both exciting new possibilities and challenges that confront researchers in this field that has become increasingly diverse and rich in theoretical insight.

This paper also shows how much and how the leadership field has developed in last 15 years. To date, it has identified a total of 66 different leadership theory domains. Notably, as it is recently highlighted in the findings, a tendency form modernist-positivist approach to interpretive/constructive approach is visible. In last decades, there is an increasing stress upon soft aspects of the leadership theories. This results in the high number of articles found in the relevancy with social context, cultural, ethical, and emotional context. Concisely, new millennium is experiencing the proliferation of leadership studies both in established theories and in emerging theories. While the majority of the articles during the inquired period are from the previously established theories, emerging theories are reportedly closing the gap faster.

On the other hand, although this diversity has been bringing forth newer perspectives that enrich body of knowledge for leadership, it also presents several challenges that future research. Notably, future research needs to develop integrative perspectives that consider how disparate leadership theories relate or operate simultaneously to influence the emergence of leadership phenomenon. Overall, new millennium is now experiencing a definition shift for the term leadership towards a phenomenon that evolves over different time spans and contingent to hierarchical levels at which leaders are investigated comparing to old school understanding which generalizes leadership as a process which occurs over indeterminate amounts of time. In order to understand this shift, scholars are now focusing on "(how) micro processes, such as perceptions, emotions, and cognitions, and macro processes, such as the social-relational context, dynamically affect follower and leader outcomes (...) to explain its role within complex systems for instigating organizational change and managing dynamic social networks" (Dinh et al., 2014: p. 37).

While the growing diversity of leadership theory is helping to create an academic agenda for leadership re- 
search within the investigated time frame, it is also introducing several challenges that accompany the rapid proliferation of new theoretical perspectives. Currently, leadership practitioners who want to use scientific knowledge to improve organizational leadership processes must select from a wide array of theories that focus on competing levels of analysis: event, individual, dyadic, group, and organizational. Leadership scholars and practitioners now face the challenge of integrating this diverse body of knowledge yielded from wide array of theories to explain how leaders shape organizational processes and systems. However, continued growth in theory and research also increases urgency for a method of organizing the extant literature.

\section{Acknowledgements}

Author extends his sincere thanks to Krzysztof Bochenek and Mustafa Sever for their editorial efforts and contributions.

\section{References}

Bono, J. E., \& Ilies, R. (2006). Charisma, Positive Emotions and Mood Contagion. The Leadership Quarterly, 17, 317-334. http://dx.doi.org/10.1016/j.leaqua.2006.04.008

Carson, J. B., Tesluk, P. E., \& Marrone, J. A. (2007). Shared Leadership in TEAMS: An investigation of Antecedent Conditions and Performance. Academy of Management Journal, 50, 1217-1234. http://dx.doi.org/10.2307/20159921

Clegg, S., \& Hardy, C. (1999). Introduction. In S. Clegg, \& C. Hardy (Eds.), Studying Organization (pp. 1-22). London: Sage.

Day, D. V. (2001). Leadership Development: A Review in Context. The Leadership Quarterly, 11, 581-613. http://dx.doi.org/10.1016/S1048-9843(00)00061-8

Denis, J. L., Lamothe, L., \& Langley, A. (2001). The Dynamics of Collective Leadership and Strategic Change in Pluralistic Organizations. Academy of Management Journal, 44, 809-837. http://dx.doi.org/10.2307/3069417

Dinh, J. E., Lord, R. G., Gardner, W. L., Meuser, J. D., Liden, R. C., \& Hu, J. (2014). Leadership Theory and Research in the New Millennium: Current Theoretical Trends and Changing Perspectives. The Leadership Quarterly, 25, 36-62. http://dx.doi.org/10.1016/j.leaqua.2013.11.005

Eagly, A. H., \& Chin, J. L. (2010). Diversity and Leadership in a Changing World. American Psychologist, 65, 216. http://dx.doi.org/10.1037/a0018957

Einarsen, S. L., Aasland, M. S., \& Skogstad, A. (2007). Destructive Leadership Behavior: A Definition and Conceptual Model. The Leadership Quarterly, 18, 207-216. http://dx.doi.org/10.1016/j.leaqua.2007.03.002

Gardner, W. L., Lowe, K. B., Moss, T. W., Mahoney, K. T., \& Cogliser, C. C. (2010). Scholarly Leadership of the Study of Leadership: A Review of the Leadership Quarterly’s Second Decade, 2000-2009. The Leadership Quarterly, 21, $922-958$. http://dx.doi.org/10.1016/j.leaqua.2010.10.003

Golden, T. D., Veiga, J. F., \& Dino, R. N. (2008). The Impact of Professional Isolation on Teleworker Job Performance and Turnover Intentions: Does Time Spent Teleworking, Interacting Face-to-Face, or Having Access to Communication Enhancing Technology Matter? Journal of Applied Psychology, 93, 1412-1421. http://dx.doi.org/10.1037/a0012722

Hatch, M. J., Kostera, M., \& Kozminski, A. K. (2007). The Three Faces of Leadership. Oxford: Blackwell.

Hogg, M. A. (2001). A Social Identity Theory of Leadership. Personality and Social Psychology Review, 5, $184-200$. http://dx.doi.org/10.1207/S15327957PSPR0503_1

House, R. J., \& Aditya, R. N. (1997). The Social Scientific Study of Leadership: Quo Vadis? Journal of Management, 23, 409-473. http://dx.doi.org/10.1177/014920639702300306

Howell, J. M., \& Shamir, B. (2005). The Role of Followers in the Charismatic Leadership Process: Relationships and Their Consequences. Academy of Management Review, 30, 96-112. http://dx.doi.org/10.5465/AMR.2005.15281435

Judge, T. A., \& Bono, J. E. (2000). Five-Factor Model of Personality and Transformational Leadership. Journal of Applied Psychology, 85, 751-769. http://dx.doi.org/10.1037/0021-9010.85.5.751

Kirkman, B. L., Chen, G., Farh, J.-L., Chen, Z. X., \& Lowe, K. B. (2009). Individual Power Distance Orientation and Follower Reactions to Transformational Leaders: A Cross-Level, Cross-Cultural Examination. Academy of Management Journal, 52, 744-764. http://dx.doi.org/10.5465/AMJ.2009.43669971

Kozminski, A. K., \& Jemielniak, D. (2013). The New Principles of Management. Warsaw: Kozminski University. http://dx.doi.org/10.3726/978-3-653-02998-7

Kozminski, A. K. (2008). Management in Transition. Warsaw: Difin. 
Liden, R. C., Wayne, S. J., Zhao, H., \& Henderson, D. (2008). Servant Leadership: Development of a Multidimensional Measure and Multi-Level Assessment. The Leadership Quarterly, 19, 161-177. http://dx.doi.org/10.1016/j.leaqua.2008.01.006

Lord, R. G., \& Shondrick, S. J. (2011). Leadership and Knowledge: Symbolic, Connectionist, and Embodied Perspectives. The Leadership Quarterly, 22, 207-222. http://dx.doi.org/10.1016/j.leaqua.2010.12.016

Lord, R. G., Hannah, S. T., \& Jennings, P. L. (2005). A Framework for Understanding Leadership and Individual Requisite Complexity. Organizational Psychology Review, 1, 104-127. http://dx.doi.org/10.1177/2041386610384757

Mehra, A., Smith, B. R., Dixon, A. L., \& Robertson, B. (2006). Distributed Leadership in Teams: The Network of Leadership Perceptions and Team Performance. The Leadership Quarterly, 17, 232-245. http://dx.doi.org/10.1016/j.leaqua.2006.02.003

Mumford, M. D., Antes, A. L., Caughron, J. J., \& Friedrich, T. L. (2008). Charismatic, Ideological, and Pragmatic Leadership: Multi-Level Influences on Emergence and Performance. The Leadership Quarterly, 19, 144-160. http://dx.doi.org/10.1016/j.leaqua.2008.01.002

Porter, L. W., \& McLaughlin, G. B. (2006). Leadership and the Organizational Context: Like the Weather? The Leadership Quarterly, 17, 559-576. http://dx.doi.org/10.1016/j.leaqua.2006.10.002

Ruvio, A., Rosenblatt, Z., \& Hertz-Lazarowitz, R. (2010). Entrepreneurial Leadership Vision in Nonprofit vs. For-Profit Organizations. The Leadership Quarterly, 21, 144-158. http://dx.doi.org/10.1016/j.leaqua.2009.10.011

Shin, S. J., \& Zhou, J. (2003). Transformational Leadership, Conservation, and Creativity: Evidence from Korea. Academy of Management Journal, 46, 703-714. http://dx.doi.org/10.2307/30040662

Treadway, D. C., Hochwarter, W. A., Ferris, G. R., Kacmar, C. J., Douglas, C., Ammeter, A. P., et al. (2004). Leader Political Skill and Employee Reactions. The Leadership Quarterly, 15, 493-513. http://dx.doi.org/10.1016/j.leaqua.2004.05.004

Uhl-Bien, M. (2006). Relational Leadership Theory: Exploring the Social Processes of Leadership and Organizing. The Leadership Quarterly, 17, 654-676. http://dx.doi.org/10.1016/j.leaqua.2006.10.007

Uhl-Bien, M., Marion, R., \& McKelvey, B. (2007). Complexity Leadership Theory: Shifting Leadership from the Industrial Age to the Knowledge Era. The Leadership Quarterly, 18, 298-318. http://dx.doi.org/10.1016/j.leaqua.2007.04.002

Vera, D., \& Crossan, M. (2004). Strategic Leadership and Organizational Learning. Academy of Management Review, 29, 222-240.

Vroom, V. H., \& Jago, A. G. (2007). The Role of the Situation in Leadership. American Psychologist, 62, 17-24. http://dx.doi.org/10.1037/0003-066X.62.1.17

Waldman, D. A., Balthazard, P. A., \& Peterson, S. J. (2011). Social Cognitive Neuroscience and Leadership. The Leadership Quarterly, 22, 1092-1106. http://dx.doi.org/10.1016/j.leaqua.2011.09.005

Yildirim, E. (2002). “Cogito Ergo Sum” dan “Vivo Ergo Sum” a Örgütsel Analiz. Yönetim Araştırmaları Dergisi, 2, 155185.

Yukl, G. (2008). How Leaders Influence Organizational Effectiveness. The Leadership Quarterly, 19, 708-722. http://dx.doi.org/10.1016/j.leaqua.2008.09.008

Zaccaro, S. J. (2007). Trait-Based Perspectives of Leadership. American Psychologist, 62, 6-22. http://dx.doi.org/10.1037/0003-066X.62.1.6 